\title{
Technical Problem Analysis of Micro Hydro Plants: A Case Study at Pokhari Chauri of Kavre District
}

\author{
Sugam Maharjan ${ }^{1}$, Rajendra Shrestha ${ }^{2}$ \\ ${ }^{I}$ Department of Mechanical Engineering, Thapathali Campus, IOE, TU, Kathmandu, Nepal \\ ${ }^{2}$ Department of Mechanical Engineering, Central Campus, Pulchowk, IOE, TU, Lalitpur, Nepal \\ Corresponding Email: rsfluid@hotmail.com
}

\begin{abstract}
In Nepal, there are number of Micro hydro plant installed each year for village electrification and income growth activity. This paper highlights on the technical problem face by existing micro-hydro systems. The study shows the technical status of micro-hydro plant needs to be improved. Most of the problems are found in civil components due to the use of locally available materials and unskilled labor in construction works. The problem associated with mechanical components is due to the mishandling of equipment and lack of preventive maintenance. In addition, the study shows that the lack of technical knowledge about the electrical and electronic components to the operator, created problems in electrical system. Thus various problem associated with micro-hydro system has been identified. For the sustainable development of micro- hydro system, the technical problem and financial problem has been analyzed.
\end{abstract}

Keywords: Micro Hydro Plant (MHP), Technical Problem

\section{Introduction}

Electricity is an important source of energy that can be developed by human being to solve a number of problems. For the development of country and economy growth activities, the electrical energy plays a vital role.

The study shows that the potential of the Micro Hydro Power in the country is 50MW (Bajracharya, 2003). Fortunately, it is estimated that in Nepal there are more than 6,000 rivers among them 500 are large enough to develop small and Micro hydro power projects (REDP, 2006).

It is more difficult from the geographical and economical point of view to electrify the rural sectors in Nepal. Micro hydro technology has proved to be one of the major mean of rural electrification in Nepal. Different organization like Alternative Energy Promotion Center (AEPC), Rural Energy Development Programs (REDP), ESAP, REP, ICIMOD, and NEA are involved for the promotion of Micro Hydro development in Nepal. AEPC has conducted the carpet study in 2009 and identified the pico and micro hydro plant projects from different districts of $16.876 \mathrm{KW}$.

Different studies have been conducted for the sustainable development of existing Micro Hydro Plants. The study has to be further done to know the actual problem of failure projects and the possible way to solve the problem for sustainable development of micro hydro power.

This paper is based on field survey of at Pokhari chauri Village development Committee (Kavre districts, Nepal). The data available and the problems are analyzed for the sustainable development of micro hydro plant. 
Failure of such a project discourages community in attempting other development projects. For the sustainability of the micro hydro plant, various technical, managerial and financial aspects plays a great role. Among them technical aspect should be sound to have reliable operation of the plant. Mainly the technical section can be divided among the Civil, Mechanical, Electro Mechanical and Electrical Components.

However, the poor technical status and the lower financial return from the MHP business have become a matter of concern for MHP sustainability, a major challenge. So the proper feasibility study and reliable installation should be done in each sector.

If we look back about the success and failure study of micro hydro plant, the study shows technical problem is a great challenge for a reliable operation of the plant. Hence it is a very importance for supporting organization and the manufacturers to study on the technical part to reduce the failure of the MHP. Thus the study mainly focuses on the technical part to give the facts about the possible problem related to MHP and the way to solve the possible problem for the sustainable development of the MHPs.

\section{Methodology}

Questionnaires were made for operator, manager, manufacturers and other related person to get an actual status of micro hydro plant. The major problems of micro hydro plant were categorized into Civil Part, Mechanical Part and Electrical Part.

The actual problems of micro hydro plant were found out by visiting the selected sites. The field visits to manufacturers and related agents were done to get a problem faced by them in their MHPs.

The major problems of micro hydro plant were analyzed to give appropriate solution. Financial analysis was carried out for the sustainability of the system in operation using Microsoft excel and simple mathematical relations.

\section{Results and Discussions}

\subsection{Comparative Maximum Power Output of Chauri Khola MHPs Each Year}

Table1: Major problems finding during the site visit

\begin{tabular}{|c|c|c|c|}
\hline Schemes & $\begin{array}{c}\text { Capacity } \\
(\mathrm{KW})\end{array}$ & $\begin{array}{c}\text { Tariff } \\
(\mathrm{Rs} / \mathrm{HH} / \mathrm{m})\end{array}$ & Major technical problems \\
\hline $\begin{array}{c}\text { Chauri Khola } 1 \\
\text { MHP }\end{array}$ & 22 & 55 & $\begin{array}{ll}\text { - } & \text { Intake washed off } \\
\text { - } & \text { Silt problem } \\
\text { - } & \text { Land slide of canal } \\
\text { - } & \text { Valve leakage } \\
\text { - } & \text { MCB tripping } \\
\text { - } & \text { Load unbalance } \\
\text { - } & \text { Generator over heated }\end{array}$ \\
\hline
\end{tabular}




\begin{tabular}{|c|c|c|c|}
\hline $\begin{array}{c}\text { Chauri Khola ll } \\
\text { MHP }\end{array}$ & 22 & 70 & $\begin{array}{ll}\text { - } & \text { Intake washed off } \\
\text { - } & \text { Valve leakage } \\
\text { - } & \text { Unsafe location of power house }\end{array}$ \\
\hline $\begin{array}{c}\text { Chauri Khola } 111 \\
\text { MHP }\end{array}$ & 22 & 75 & $\begin{array}{ll}\text { - } & \text { Land slide of canal } \\
\text { - } & \text { Valve leakage } \\
\text { - } & \text { Access to national grid } \\
\text { - } & \text { Electronic load controller (ELC) not } \\
\text { working properly }\end{array}$ \\
\hline $\begin{array}{l}\text { Chauri Khola } \\
\text { IV MHP }\end{array}$ & 45 & 100 & $\begin{array}{ll}\text { - } & \text { Intake washed off } \\
\text { - } & \text { Design problem } \\
\text { - } & \text { Valve leakage } \\
\text { - } & \text { Low power output } \\
\text { - } & \text { Expansion joint not working properly } \\
\text { - } & \text { MCB tripping } \\
\text { - } & \text { Unsafe location of power house }\end{array}$ \\
\hline $\begin{array}{c}\text { Chauri Khola V } \\
\text { MHP }\end{array}$ & 29 & 100 & $\begin{array}{ll}\text { - } & \text { Intake washed off } \\
\text { - } & \text { Land slide of canal } \\
\text { - } & \text { Valve leakage } \\
\text { - } & \text { Light short circuit }\end{array}$ \\
\hline
\end{tabular}

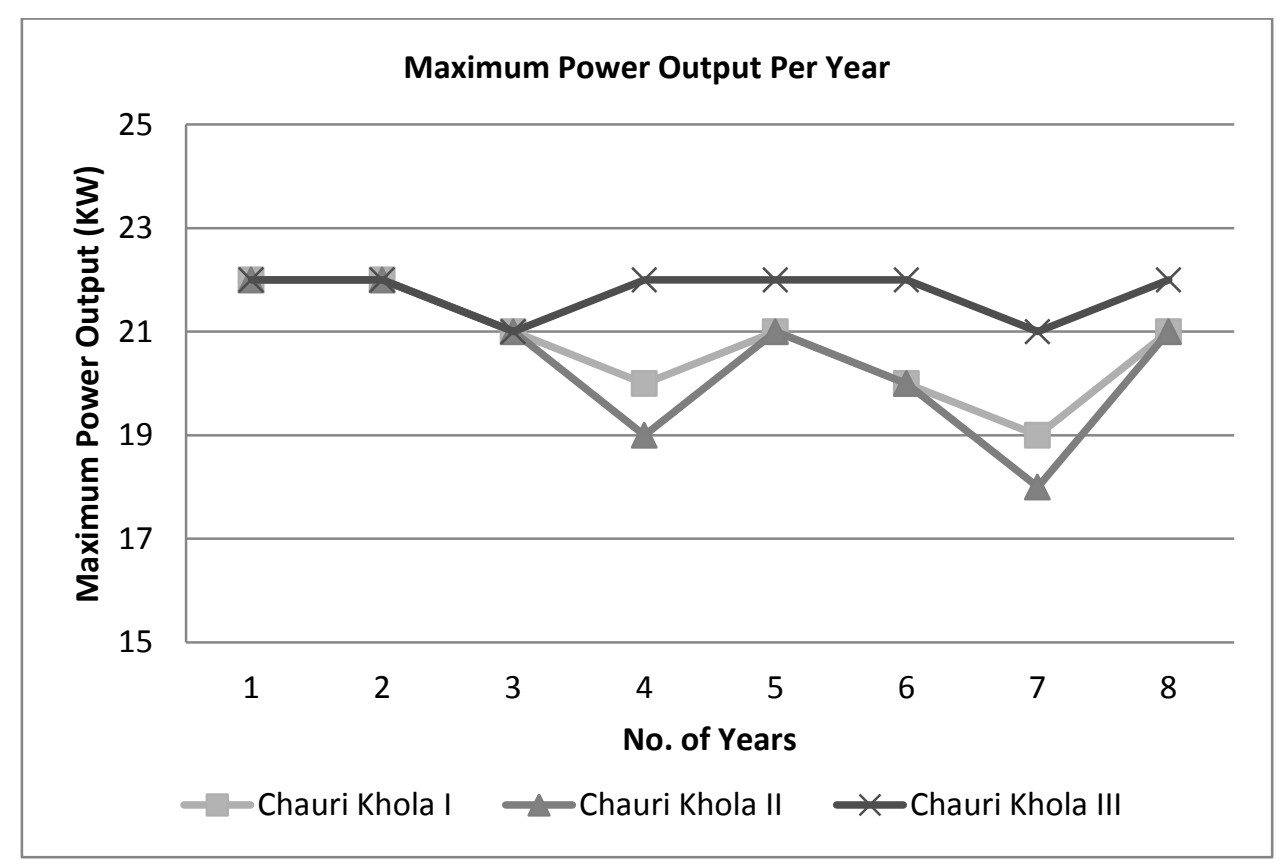

Figure 1: Maximum Power Output of Chauri Khola MHPs

Figure 1 shows how the variation of average power output each year of different MHPs during the running period. In case of Chauri Khola I MHP, the plant is running with full load capacity 
during first two year of operation. The decrease in power output during four years of operation is due to the problem of valve leakage, bearing problem, turbine-runner wear and tear.

It is noticed that the power output reduce to eighteen KW of Chauri Khola II MHP during the seven year of operation is due to bearing problem, valve leakage and again turbine-runner wear and tear.

As silt problem is the major problem of all rivers in Nepal, proper attention should be given to reduce sill effect. It is observed in Chauri Khola I MHP has the high canal gradient and silt problem make the wear and tear of turbine blade quickly as compare to other schemes.

In case of Chauri khola II MHP, the data shows the decreasing nature of power output is due to lower system efficiency. This kind of problem occurs mainly in lower economic projects. This is due to less regular and preventive maintenance had been performed. The power output is increased after the maintenance of the turbine unit. As poor financial status, it is difficult to take preventive and corrective maintenance.

In case of Chauri Khola III MHP, the little change in the variation of maximum power output. The preventive and schedule maintenance of the plant keeps the minimum power loss and system is more stable.

\subsection{Annual Repair and Maintenance Cost of MHPs:}

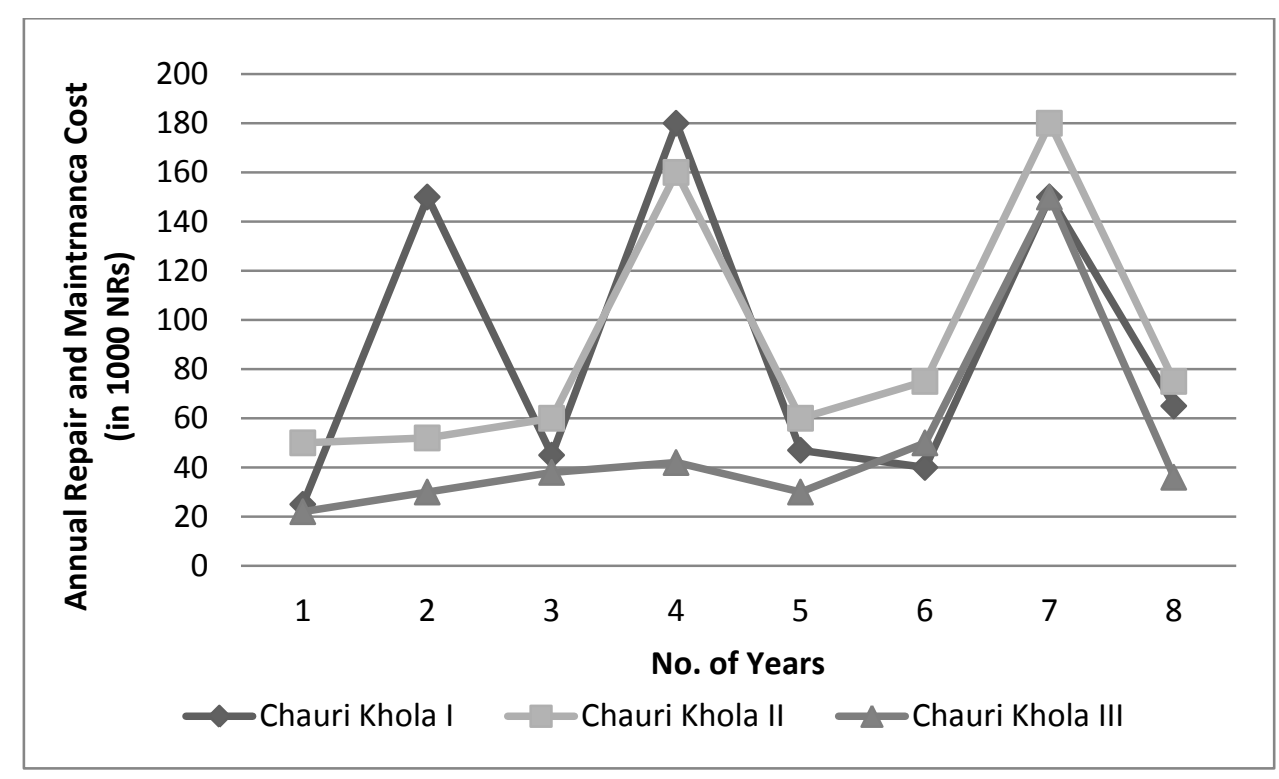

Figure 2: Annual Repair and Maintenance Cost of MHPs

The fluctuation in the variation of annual repair and maintenance cost is due to the minor and major repair and maintenance.

Due to the canal problem of Chauri Khola I MHP, the earthen canal is replace by the lined canal and thus increase in repair and maintenance cost during the first two year of operation. The major repair and maintenance for plant occurred during first four years and seventh year's maintenance is due to the replacement of bearing and repair of turbine blades. 
The above figure shows the general trend and the period of maintenance requires during the operation of a plant. Thus it is very helpful to take a preventive maintenance of a plant before the major problem occurs. Beside that it shows how the maintenance cost is increasing during the running period for economical project in term of quality.

It is found that, the repair and maintenance of intake and canal has to be done each year due to their temporary structures. Though the initial cost is high, it's better to improve weir structure to prevent from flood during the rainy season.

In case of Chauri Khola I MHP, the plant has poor technical and financial status. Major problem in the plant has occurred due to less preventive maintenance, during its operation period. Thus the preventive maintenance is very important to minimize the major repair and maintenance.

In case of Chauri Khola III MHP, there is little variation in expenditure of repair and maintenance cost. The Plant is technically sound. The proper preventive maintenance makes the plant more reliable and functions effectively. The major repairing cost occurs during the seventh year of operation is due to wear and tear of turbine unit. This data concludes proper preventive maintenance reduces repair and maintenance cost.

\subsection{Average Shutdown Days within a Year due to Canal problem:}

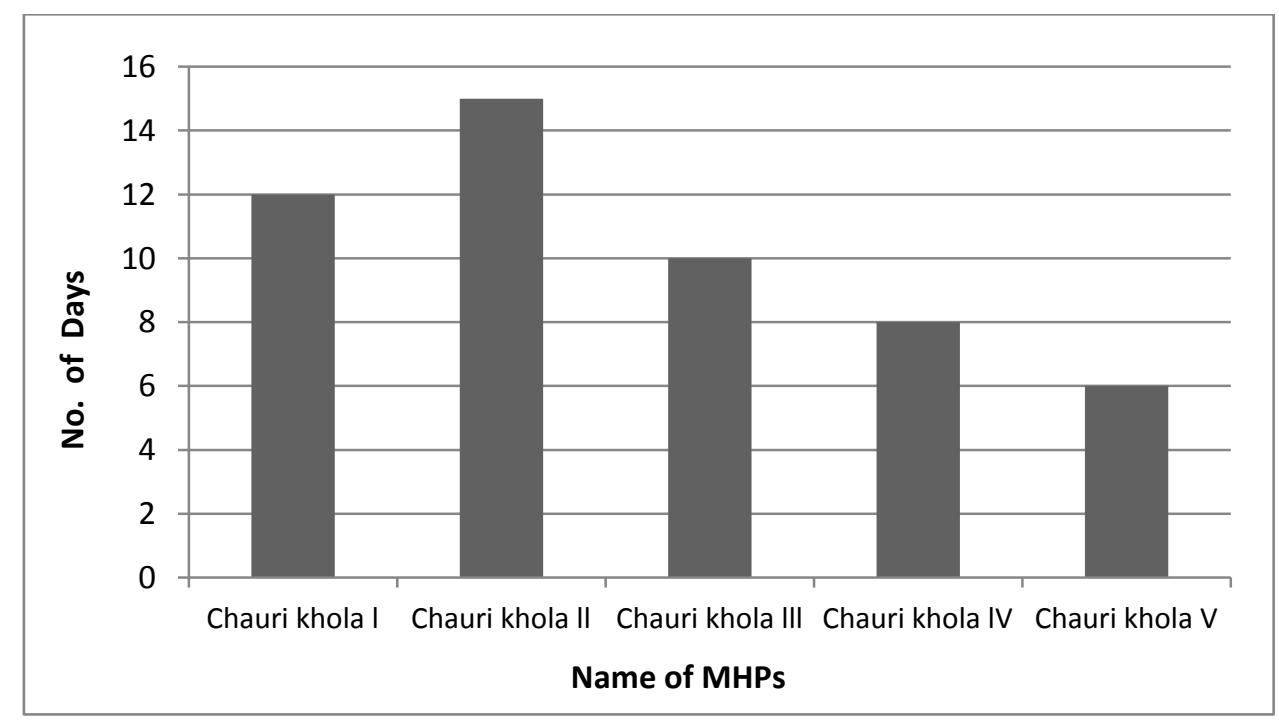

Figure 3: Average shut down days due to canal problem within the year 2010

Figure 3 shows the average shut down period in days due to canal problem within a year. The canal used in Chauri Khola I MHP and Chauri Khola II MHP are mixed (earth and lined) canal where as remaining sites canal are lined type.

The problem occurs in mixed type canal is due to the land slide, flood and soil instability. Thus the Figure shows the increase in number of days to repair and maintenance of canal as compare to lined type. Beside these cause, the canal gradient and seepage is important factor to be considered.

So the proper survey for safe route for canal in term of landslide, flood has to be considered. The gradient of canal should be appropriate to reduce the damage and silt problem. 


\subsection{Comparative Analysis based on Cost:}

The most of the Micro Hydro Plants are installed on the economical basis. The Table 2 below shows the comparative study of same capacity turbine (22 KW Turbine as a Case Study) having varying efficiency.

Similarly the cost of bearing and belt are varying based on quality and service life. Obviously the high initial cost result gives high output efficiency of the plant.

Table 2: Comparative Analysis based on Cost

\begin{tabular}{|l|c|c|}
\hline Description & T12 Model Cross Flow Turbine & T15 Model Cross Flow Turbine \\
\hline Turbine Cost (NRs) & $3,00,000$ & $4,00,000$ \\
\hline Bearing Cost (NRs) & 10,0000 & 24,0000 \\
\hline \multirow{2}{*}{ Belt Cost (NRs) } & 2000 & 25,0000 \\
& (V-belt) & (Flat Belt) \\
\hline & $3,12,000$ & $4,29,000$ \\
\hline \multicolumn{2}{|c|}{ Source (Housing Company Service Pvt. Ltd, Nepal, 2010) } \\
\hline
\end{tabular}

Efficiency of T12 Turbine

Efficiency of T15 Turbine

Generator Efficiency

Transmission Efficiency

Increase investment cost

Improve in Efficiency

Increase in power output

Increase in number in household

Monthly income from increase household

Yearly income from increase household

Increase in daily operating hour of end use

Increase in consumption by end use

Increase income from end use

Annual income from end use

Net increase income

Payback period

$$
=55 \%
$$

$=60 \%$

$=95 \%$

$=90 \%$

$=$ NRs. $1,17,000$

$=5 \%$

$=1.8 \mathrm{KW}$

=18@100 W per household

$=1350 @($ Rs. 75 per month per household $)$

$=$ NRs. 16200

$=6 \mathrm{hrs}$.

$=1.8 \mathrm{KW} * 6 \mathrm{~h} \quad=10.8 \mathrm{KWh}$.

$=10.8 \mathrm{KWh} *$ NRs. $6 / \mathrm{KWh}=\mathrm{NRs} .64 .8$

$=$ NRs. $64.8 * 270=$ NRs. 17496

$=$ NRs. $16200+$ Rs. $17496=$ NRs. 33696

$=$ Increase investment cost / Net increase income

= NRs. 1, 17,000 / Rs. 33696

$=3.47$ years 
The financial analysis shows that simple pay back period is 3.47 years. Thus though the initial project cost is high, it's better to use of higher efficiency turbine and better quality of machine components.

The reduction in repair and maintenance cost; and reliable function of the plant are the major factors for the sustainable development.

\section{Conclusions}

For all MHPs, shut down period of power house due to faults in intake, canal, forbay are about eighteen to twenty four days each year. Every year, the repair and maintenance cost is increased due to the civil component's problem.

The proper feasibility study has to be done for site selection of intake, safe route of canal, forbay and desilting basin and power house. The effect of landslide and flood should be minimized to MHP for reliable operation. The technical person should be appointed in the construction work. The canal gradient, deslitting basin and forbay should be constructed as per guidelines provided. The Sluice Gate can be used instead of using Flushing Cone for easy flushing of silt. The flushing system should be done periodically to reduce the effect of silt.

Most of the problems found in mechanical components are bearing, erosion on turbine blade. The bearing problem is due to the less regular maintenance, misalignment and improper handling of equipments. The turbine erosion occurs due to heavy silt flow as the system defects.

The leakage of valve is the major problem that has been found. To improve this, preventive maintenance of gasket has to be done to prevent from leakage.

It is found that the mechanical components has used up to a critical condition causing a measure problem in MHP system.

The existing used of mild steel for flow controlling valve should be replaced by the cast iron or cast steel to minimize the erosion caused by silt. The surface hardening of flow controlling valve should be done to improve its efficiency. The sealing mechanism of the valve should be modified to prevent from leakage. The leveling of the machine foundation must be done by technical person to increase the turbine, bearing and belt life. The robust and good quality of machine components should be used in Micro Hydro Plant to reduce the repair and maintenance cost in future.

Molded case circuit breaker (MCCB) should not be used as switch. The proper size of MCCB should be selected to protect the system from short circuit and over loaded condition. The lighting arrestor should be placed as per guidelines to minimize the effect of lighting discharge. The wooden pole used for transmission should be replaced by metallic pole to reduce the repair and maintenance cost as well as safety point of view.

The repair and maintenance of micro hydro components is difficult due to far access of repair centre. The standard spare parts like good quality of bearing, grease, belt, MCCB, fuse, thyrister, lighting arrestor and contactor should be stocked for reliable operation of the MHPs

The operator has to be trained during the manufacturing assembly and installation period to give the proper knowledge about the various components of MHPs. 


\section{References}

[1] Harvey Adam, 1998, Micro-Hydro Design Manual, A Guide to small- Scale Waterpower Scheme.

[2] Hydro Consult (P) Ltd, July 2005, Study of Functional Status of Micro Hydro Power Projects .

[3] Dr.T. R. Bajracharya, 2006 Course Manual on Mini and Micro Hydropower System Design.

[4] Rajbhandari, Sujit Man, Setemper 2007, Comparative Study of Civil Components of Selected Micro Hydro Plant in Nepal.

[5] Gyawali P, 2004, A Study on Cost Reduction Possibility in Mechanical Components of Micro Hydro Power System.

[6] Earth Consult (P) Nepal, July 2005, A report of Random Sample Survey to determine actual status of private Micro power plants in Nepal.

[7] AEPC, January 2010, Micro-Hydro Implementation Guideline .

[8] ICIMOD,1998, Repair and Maintenance Manual For Private Micro-Hydro Power Plants. 